104

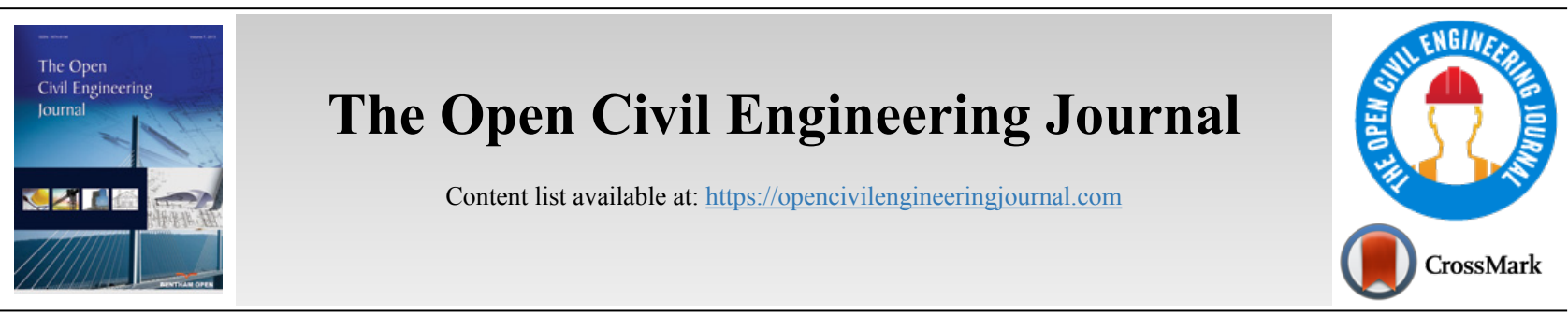

RESEARCH ARTICLE

\title{
Evaluating Fresh and Hardened Properties of High-Strength Concrete Including Closed Steel Fibres
}

\author{
Sarah Al-Qutaifi ${ }^{1, *}$ and Ali Bagheri ${ }^{2}$ \\ ${ }^{I}$ Department of Construction and Projects, Thi-Qar University, Nasiriyah, Iraq \\ ${ }^{2}$ Faculty of Science Engineering and Technology, Swinburne University of Technology, Melbourne, Australia
}

\begin{abstract}
:
Background:

The tensile strength of the plain concrete is weak. Thus, fibres are embedded in concrete to improve its ductility. However, pulling out steel fibres from concrete structures is one of the most encountered issues in the fiber-reinforced concrete, which hinders using their maximum capacities.

\section{Objectives:}

Thus, closed steel fibres (square shape) were incorporated into concrete mixes to evaluate their impacts against the pulling-out effects and assess the feasibility of applying Closed Steel Fibres (CSFs) on the fresh and hardened concrete properties. Hooked end and straight steel fibres were also investigated for comparison.
\end{abstract}

Methods:

The utilized steel fibres were incorporated with lengths of 20,30 , and $40 \mathrm{~mm}$, and volume fractions of $0.25 \%, 0.50 \%$, and $0.75 \%$. Silica Fume (SF) was involved in the fibre-reinforced concrete mixtures at $7 \%$ of the cement weight.

Results:

Paper outcomes stated that the inclusion of steel fibres involved different impacts on the concrete compressive strength depending on the applied fibre geometries and content.

\section{Conclusion:}

CSFs exhibited better performance against the pulling-out effect from the surrounding concrete structure than those of hooked end and straight steel fibres. However, the addition of CSFs has increased the concrete permeability due to their poor space-filling capacity.

Keywords: Closed steel fibres, Fibre-reinforced concrete, Compressive strength, Splitting tensile strength, Flexural strength, Silica fume.

\begin{tabular}{l|l|l|l} 
Article History & Received: December 4, 2020 & Revised: February 15, 2021 & Accepted: February 16, 2021
\end{tabular}

\section{INTRODUCTION}

Concrete is the most widely applied construction material $[1$ - 3]. It possesses a variety of desirable characteristics correlated to availability, affordability, ease of usage, etc., [4]. However, the material strength and structural performance of the ordinary Portland concrete aren't sufficiently compatible with concrete constructions located in severe environments and subjected to sizable static or dynamic loads. Throughout the previous few years, there have been considerable efforts allo-

\footnotetext{
" CAddress correspondence to this author at Department of Construction and Projects, Thi-Qar University, Nasiriyah, Iraq; Tel: +9647814607799;
}

E-mail: sarahmajeed2013@yahoo.com.au cated in enhancing the concrete material strength by incorporating specific percentages of additives or reinforced fibres into concrete mixtures. Consequently, some new concrete categories have been created in the last few decades, i.e. HighStrength Concrete (HSC), High-Performance Concrete (HPC), and Fibre-Reinforced Concrete (FRC). They have been produced to match with huge developments in the construction sector and comply with the basic construction requirements e.g., strength, durability, toughness, etc., [4 - 6]. Hence, the addition of mineral admixtures (geopolymers or pozzolanic) has been promoted into concrete mixtures as a partial replacement to enhance the concrete performance [7 - 14]. Thus, the blended cement demands rose globally to manufacture HSC 
with low permeability, high density, and durability [15]. Nevertheless, the cost of HSC is higher than the normal strength concrete (OPC). Therefore, it is proposed to restrict its usage in the critical concrete structures subjected to harsh environments, extreme climate, or overweight static and dynamic loads [16, 17].

However, it has been observed that the concrete brittleness increases with enhancing its material strength [4, 18 - 21]. Therefore, various types of reinforced fibres have been incorporated into concrete mixtures to enhance their crack resistance, tensile strength, shear strength, flexural strength, energy absorption, and ductility [17, 20, 22, 23]. Fibres are also utilized to improve the performance of some structural elements in different concrete constructions. They contribute to improving the bonding strength between reinforcing steel bars and the concrete matrix under monotonic loading, enhancing the cyclic loading, preventing spalling, protecting the concrete cover under considerable deformations, and maintaining the structural integrity from buckling reinforcing bars in columns [22, 24 - 26]. Fibres embedded into concrete mixtures are classified according to several aspects. Firstly, they are characterized based on their materials: natural mineral (rock-wool, asbestos, etc.); natural organic (bamboo, sisal, cellulose, jute, etc.); or man-made, e.g., polymers, steel, glass, titanium, carbon, etc. Second is according to their chemical/physical characteristics, e.g., density, chemical stability, non-reactivity, surface roughness, flammability, fire resistance, etc. Third is according to the fibre hardened properties, e.g., ductility, stiffness, tensile strength, elastic modulus, surface adhesion properties, etc. Fourth is based on the fibre geometric properties e.g., diameter, length, longitudinal profile, or crosssectional shape [22, 24, 27, 28]. However, steel fibres are the most applied reinforced fibre materials into concrete structures that can contribute to their high strengths, accessibility, and affordability $[4,23,29]$. Accordingly, their impacts on the hardened properties of HSC have been broadly inspected [30 - 34].

The literature has stated that the addition of Steel Fibres (SFs) into concrete mixes results in considerable developments in the bending strength and splitting tensile strength [32, 33, $35,36]$. Nevertheless, conflicting findings have been reported regarding their effects on the concrete compressive strength $[4$, 35 - 39]. However, pulling out of SFs from the surrounding concrete is one of the most encountered issues in FRC. Consequently, that impedes utilizing the full strength of steel fibres under the external loads. Specifically, the bond strength between embedded SFs and the concrete structure is rather affected by the combination of the concrete paste adhesion, mechanical anchorage, and friction [35]. In the previous few years, several investigations have been allocated to inspect the impact of different fibre geometries on the hardened properties of FRC. Some studies have concentrated on optimizing the mechanical anchorage of SFs to enhance the bonding strength between steel fibres and the concrete matrix. Twisted, cone end, hooked end, crimped steel fibres are some of the examples of developed reinforced SFs. Although, they show better behaviour against pull outing from surrounding concrete under the applied loading than that achieved by Straight Steel Fibres (SSFs). Nevertheless, the failure of FRC is still initiated by pulling out embedded SFs. Therefore, square steel fibres with a dimension of $17 \mathrm{~mm} \times 17 \mathrm{~mm}$ have been suggested to control the pulling out of steel fibre from a concrete structure and then using their maximum capacity [35]. The authors indicated that square steel fibres have a better impact on improving concrete strength compared to that of SSFs. However, the effects of different dimensions of square steel fibre on the green and mechanical concrete properties have not been discussed in previous papers. Therefore, this current paper aims to inspect the efficiency of developing new types of closed steel fibres in a square form to enhance the bonding strength between steel fibres and a surrounding concrete matrix. Thus, variant lengths and content of straight, hooked end, and closed (square) steel fibres were applied into concrete mixtures to inspect and compare their effects on the green and mechanical properties of blended or High Strength Concrete (HSC).

\section{MATERIALS AND METHODS}

\subsection{Materials}

The applied cementitious materials were OPC and SF. Based on the X-ray Fluorescence analysis, the chemical composition and Loss on Ignition (LOI) of OPC and SF are involved in Table 1. Silica fume was applied as an additive material at $7 \%$ of cement weight in all fibre-reinforced concrete mixes. The specific gravity and average surface area of the used SF were 2.23 and $20000 \mathrm{~m}^{2} / \mathrm{kg}$, respectively. Also, Sand (S) and Gravel $(\mathrm{G})$ were used with the max particle size of 4.0 and $9.5 \mathrm{~mm}$, respectively (Fig. 1). The water absorption and specific gravity of the applied sand and gravel were $1.28 \%$, $2.63,0.68 \%$, and 2.67 , respectively. Superplasticizer (Carboxylic $110 \mathrm{M}$ ) was also utilized to adjust the concrete flowability and eliminate the high-water demands. Three different types of steel fibres were also involved in concrete mixes, i.e. Straight Steel Fibres (SSFs), Hooked End Steel Fibres (HEFs), and Closed Steel Fibres (CSFs). They were incorporated with three different lengths of 20,30 , and $40 \mathrm{~mm}$ and volume fractions $(\mathrm{V} \%)$ of $0.25,0.50$, and 0.75 . The properties of the applied steel fibres are summarized in Table 2. In this study, the applied cementitious materials, aggregate, Superplasticizer (SP), HEFs, and SSFs were commercially available products. CSFs were manufactured in a special order just for the experiment purpose. The metal plates used in producing CSFs involved comparable physical properties to those of HEFs and SSFs to realize accurate comparison.

\subsection{Mixing Procedure \& Sample Preparations}

The experimental procedure of this paper involved 29 different concrete mixtures in total, two reference mixtures (plain, and blended), and 27 fibre-reinforced concrete mixtures. The reference Plain Concrete Mixture (RFC) was excluded from fibres and additional materials, while the Reference Blended Concrete mixture (RBC) included SF7\%. Also, 27 fibre-reinforced mixes involved $\mathrm{SF} 7 \%$ as well as different geometries and volume fractions of steel fibres. More specifically, nine fibre reinforced concrete mixtures were prepared with each fibre type to study and compare the impact of three fibre lengths of 20,30 , and $40 \mathrm{~mm}$ and volume fractions of $0.25 \%, 0.50 \%$, and $0.75 \%$ on the hardened properties of blended concrete (RBC). 
Table 1. Chemical and physical properties of cementitious materials.

\begin{tabular}{|c|c|c|}
\hline \multicolumn{3}{|c|}{ Chemical Properties } \\
\hline Composition (\%) & OPC & SF \\
\hline $\mathrm{AL}_{2} \mathrm{O}_{3}$ & 5.37 & 0.68 \\
\hline $\mathrm{SiO}_{2}$ & 20.74 & 94.2 \\
\hline $\mathrm{CaO}$ & 63.21 & 0.37 \\
\hline $\mathrm{MgO}$ & 1.08 & 1.1 \\
\hline $\mathrm{Fe}_{2} \mathrm{O}_{3}$ & 3.87 & 0.38 \\
\hline $\mathrm{Na}_{2} \mathrm{O}$ & - & 0.43 \\
\hline $\mathrm{K}_{2} \mathrm{O}$ & 0.61 & 0.94 \\
\hline LOI & - & 0.47 \\
\hline $\mathrm{C}_{3} \mathrm{~S}$ & 52.36 & - \\
\hline $\mathrm{C}_{2} \mathrm{~S}$ & 21.82 & - \\
\hline $\mathrm{C}_{3} \mathrm{~A}$ & 6.43 & - \\
\hline $\mathrm{C}_{4} \mathrm{AF}$ & 10.47 & - \\
\hline \multicolumn{3}{|c|}{ Physical Properties } \\
\hline Specific gravity & 3.2 & 2.23 \\
\hline Specific surface $\left(\mathrm{m}^{2} / \mathrm{kg}\right)$ & 300 & 20,000 \\
\hline Colour & Grey & Dark grey \\
\hline
\end{tabular}

The proportion of the Reference Plain Concrete mixture (RPC) was designed based on a target 28 compressive strength of $34 \mathrm{MPa}$, it was achieved through several trials. All concrete mixtures included Portland cement (ASTM-Type1), sand (S), and Gravel (G) with a maximum particle size of 4 and $9.5 \mathrm{~mm}$, respectively. Also, a superplasticizer (Carboxylic $110 \mathrm{M}$ ) was applied in different percentages to adjust the concrete flowability and reduce the high-range water-demands. The ratio of water/cementitious materials, sand/cement, and gravel/ cement in all concrete mixes were $0.35,1.6$ and 1.7, respectively. For more details, Table 3 involves the proportion of applied concrete mixtures. The mixing procedure of each concrete specimen has started with dry mixing for aggregate materials (sand and gravel) for $2 \mathrm{~min}$. Next, water was added gradually to make them saturated enough, this process was taken about 12 min. After that, the cementitious materials (OPC and SF) were added gradually and mixed with the remaining mixing water for $5 \mathrm{~min}$. Then, fibre reinforced materials were spread into the paste and mixed for $1 \mathrm{~min}$. At the last stage of the mixing process, Superplasticizer (SP) was added into concrete mixes in different percentages, according to the required workability, as seen in Table 4.

Table 2. Physical properties of applied steel fibres.

\begin{tabular}{|c|c|c|c|c|c|c|c|c|c|c|}
\hline No. & $\begin{array}{l}\text { Type of } \\
\text { Fibre }\end{array}$ & Fibre Shape & Fibre ID & $\begin{array}{c}\text { Length L } \\
(\mathrm{mm})\end{array}$ & $\begin{array}{c}\text { Diameter (D) } \\
(\mathrm{mm})\end{array}$ & $\begin{array}{l}\text { Aspect } \\
\text { Ratio } \\
\text { (L/d) }\end{array}$ & $\begin{array}{l}\text { Density } \\
\left(\mathrm{kg} / \mathrm{m}^{3}\right)\end{array}$ & $\begin{array}{c}\text { Tensile } \\
\text { Strength } \\
\left(\mathbf{N} / \mathbf{m m}^{2}\right) \\
\end{array}$ & $\begin{array}{c}\text { Modulus of } \\
\text { Elasticity (MPa) }\end{array}$ & Steel Fibre Shapes \\
\hline 1 & Steel & Straight & SSF & 20 & 0.40 & 50 & 7.80 & 1350 & 200,000 & $\square$ \\
\hline 2 & Steel & Straight & SSF & 30 & 0.55 & 55 & 7.80 & 1300 & 200,000 & \\
\hline 3 & Steel & Straight & SSF & 40 & 0.65 & 62 & 7.80 & 1200 & 200,000 & \\
\hline 4 & Steel & Hooked end & HEF & 20 & 0.40 & 50 & 7.80 & 1350 & 200,000 & $\longrightarrow$ \\
\hline 5 & Steel & Hooked end & HEF & 30 & 0.55 & 55 & 7.80 & 1300 & 200,000 & $\nu^{\nu}$ \\
\hline 6 & Steel & Hooked end & HEF & 40 & 0.65 & 62 & 7.80 & 1200 & 200,000 & r \\
\hline 7 & Steel & Closed (Square) & CSF & 20 & 0.40 & 50 & 7.80 & 1350 & 200,000 & \\
\hline 8 & Steel & Closed (Square) & CSF & 30 & 0.55 & 55 & 7.80 & 1300 & 200,000 & \\
\hline 9 & Steel & Closed (Square) & CSF & 40 & 0.65 & 62 & 7.80 & 1200 & 200,000 & \\
\hline
\end{tabular}




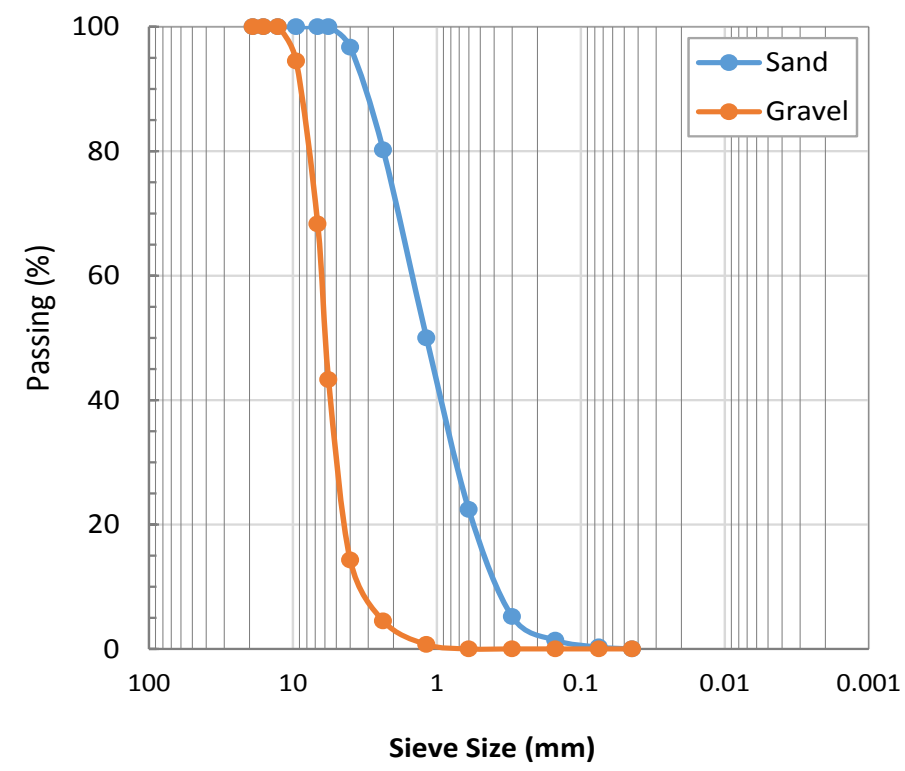

Fig. (1). Grading curves of applied aggregates.

\subsection{Sample Preparations and Testing Procedure}

The effects of different steel fibre geometries and volume fractions on the green concrete properties were evaluated in terms of the workability and air void. Slump tests were performed to estimate the flowability of different concrete mixtures in accordance with ASTM C143/C143M [40]. The testing procedure of the air content was conducted according to ASTM C138/C138M [41]. While the effects of SF and different reinforced steel fibres on the mechanical concrete properties were assessed based on the 28 days compressive strength, splitting tensile strength, and flexural strength. The preparation process of concrete specimens has started with preparing the specified moulds. The concrete was placed into the prepared moulds and then compacted on the vibrating table. The vibration process is an important step to achieve better consolidation, place concrete correctly in the used mould, and eliminate entrapped air resulted during the mixing process. All concrete samples were de-moulded after $24 \mathrm{hr}$., then cured with water according to ASTM C192/C192M till the testing day. Three compressions and splitting tensile strength tests have been conducted on cylindric concrete specimens for each mix design in accordance with ASTM C39/C39M and ASTM C496/C96M, respectively [42, 43]. The cylindrical specimens were cast with $150 \mathrm{~mm}$ diameter and $300 \mathrm{~mm}$ height for the compression and splitting tensile strength tests. While threepoint bending tests have been performed for prismatic concrete samples at the age of 28 days in accordance with ASTM C1609/C1609 M [44]. The prismatic specimens were with a cross-section of $100 \mathrm{~mm} \times 100 \mathrm{~mm}$ and a length of $500 \mathrm{~mm}$. The 28-day concrete strength results were the average of three tests conducted for each mix design.

\section{Table 3. Mix design of different concrete mixes.}

\begin{tabular}{|c|c|c|c|c|c|c|c|c|c|}
\hline $\begin{array}{l}\text { Mix } \\
\text { No. }\end{array}$ & $\begin{array}{l}\text { Mixture } \\
\text { (ID) }\end{array}$ & $\begin{array}{c}\text { OPC } \\
\left(\mathrm{kg} / \mathrm{m}^{3}\right)\end{array}$ & $\begin{array}{c}\mathrm{SF} \\
\left(\mathrm{kg} / \mathrm{m}^{3}\right)\end{array}$ & $\begin{array}{c}\mathrm{S} \\
\left(\mathrm{kg} / \mathrm{m}^{3}\right)\end{array}$ & $\begin{array}{c}G \\
\left(\mathrm{~kg} / \mathrm{m}^{3}\right)\end{array}$ & $\begin{array}{c}W \\
\left(\mathrm{~kg} / \mathrm{m}^{3}\right)\end{array}$ & Steel Fibres & $V(\%)$ & SP \% \\
\hline 1 & RPC & 500 & - & 800 & 850 & 175 & - & - & 0.8 \\
\hline 2 & $\mathrm{RBC}$ & 465 & 35 & 800 & 850 & 175 & - & - & 1.0 \\
\hline 3 & S20-0.25\% & 465 & 35 & 800 & 850 & 175 & SSF & 0.25 & 1.0 \\
\hline 4 & S20-0.50\% & 465 & 35 & 800 & 850 & 175 & SSF & 0.50 & 1.0 \\
\hline 5 & $\mathrm{~S} 20-0.75 \%$ & 465 & 35 & 800 & 850 & 175 & SSF & 0.75 & 1.0 \\
\hline 6 & S30-0.25\% & 465 & 35 & 800 & 850 & 175 & SSF & 0.25 & 1.0 \\
\hline 7 & $\mathrm{~S} 30-0.50 \%$ & 465 & 35 & 800 & 850 & 175 & SSF & 0.50 & 1.0 \\
\hline 8 & S30-0.75\% & 465 & 35 & 800 & 850 & 175 & SSF & 0.75 & 1.0 \\
\hline 9 & $\mathrm{~S} 40-0.25 \%$ & 465 & 35 & 800 & 850 & 175 & SSF & 0.25 & 1.0 \\
\hline 10 & $\mathrm{~S} 40-0.50 \%$ & 465 & 35 & 800 & 850 & 175 & SSF & 0.50 & 1.0 \\
\hline 11 & $\mathrm{~S} 40-0.75 \%$ & 465 & 35 & 800 & 850 & 175 & SSF & 0.75 & 1.1 \\
\hline 12 & $\mathrm{H} 20-0.25 \%$ & 465 & 35 & 800 & 850 & 175 & $\mathrm{HEF}$ & 0.25 & 1.0 \\
\hline 13 & $\mathrm{H} 20-0.50 \%$ & 465 & 35 & 800 & 850 & 175 & HEF & 0.50 & 1.1 \\
\hline 14 & $\mathrm{H} 20-0.75 \%$ & 465 & 35 & 800 & 850 & 175 & HEF & 0.75 & 1.1 \\
\hline 15 & H30-0.25\% & 465 & 35 & 800 & 850 & 175 & HEF & 0.25 & 1.1 \\
\hline
\end{tabular}


(Table 3) contd.....

\begin{tabular}{|c|c|c|c|c|c|c|c|c|c|}
\hline $\begin{array}{l}\text { Mix } \\
\text { No. }\end{array}$ & $\begin{array}{l}\text { Mixture } \\
\text { (ID) }\end{array}$ & $\begin{array}{c}\text { OPC } \\
\left(\mathrm{kg} / \mathrm{m}^{3}\right)\end{array}$ & $\begin{array}{c}\text { SF } \\
\left(\mathrm{kg} / \mathrm{m}^{3}\right)\end{array}$ & $\begin{array}{c}\mathrm{S} \\
\left(\mathrm{kg} / \mathrm{m}^{3}\right)\end{array}$ & $\begin{array}{c}G \\
\left(\mathrm{~kg} / \mathrm{m}^{3}\right)\end{array}$ & $\begin{array}{c}\mathrm{W} \\
\left(\mathrm{kg} / \mathrm{m}^{3}\right)\end{array}$ & Steel Fibres & V (\%) & SP \% \\
\hline 16 & H30-0.50\% & 465 & 35 & 800 & 850 & 175 & HEF & 0.50 & 1.2 \\
\hline 17 & H30- $0.75 \%$ & 465 & 35 & 800 & 850 & 175 & $\mathrm{HEF}$ & 0.75 & 1.3 \\
\hline 18 & $\mathrm{H} 40-0.25 \%$ & 465 & 35 & 800 & 850 & 175 & HEF & 0.25 & 1.2 \\
\hline 19 & H40-0.50\% & 465 & 35 & 800 & 850 & 175 & HEF & 0.50 & 1.3 \\
\hline 20 & $\mathrm{H} 40-0.75 \%$ & 465 & 35 & 800 & 850 & 175 & HEF & 0.75 & 1.3 \\
\hline 21 & C $20-0.25 \%$ & 465 & 35 & 800 & 850 & 175 & $\mathrm{CSF}$ & 0.25 & 1.3 \\
\hline 22 & C $20-0.50 \%$ & 465 & 35 & 800 & 850 & 175 & $\mathrm{CSF}$ & 0.50 & 1.3 \\
\hline 23 & C20-0.75\% & 465 & 35 & 800 & 850 & 175 & $\mathrm{CSF}$ & 0.75 & 1.4 \\
\hline 24 & C30-0.25\% & 465 & 35 & 800 & 850 & 175 & $\mathrm{CSF}$ & 0.25 & 1.3 \\
\hline 25 & C30-0.50\% & 465 & 35 & 800 & 850 & 175 & $\mathrm{CSF}$ & 0.50 & 1.4 \\
\hline 26 & C $30-0.75 \%$ & 465 & 35 & 800 & 850 & 175 & $\mathrm{CSF}$ & 0.75 & 1.4 \\
\hline 27 & C $40-0.25 \%$ & 465 & 35 & 800 & 850 & 175 & $\mathrm{CSF}$ & 0.25 & 1.3 \\
\hline 28 & C $40-0.50 \%$ & 465 & 35 & 800 & 850 & 175 & $\mathrm{CSF}$ & 0.50 & 1.4 \\
\hline 29 & C $40-0.75 \%$ & 465 & 35 & 800 & 850 & 175 & $\mathrm{CSF}$ & 0.75 & 1.6 \\
\hline
\end{tabular}

\section{RESULTS \& DISCUSSION}

\subsection{Fresh Properties}

The results of slump tests and air content are demonstrated in Figs. (2 and 3), respectively. The literature has indicated that the inclusion of supplementary materials and reinforced fibres into concrete mixes decrease the flowability of concretes [35, 45 - 48]. The slump test results of this paper confirm previous findings that the additions of silica fume (SF7\%) and steel fibres into concrete mixes caused a decline in the concrete workability in comparison with that of the Reference Plain Concrete (RPC). More specifically, SF is distinguished by its high reactivity and that refers to its high surface area and smallest particle size, which necessities more water or SP for the chemical reaction of its cementitious compounds [45, 46]. Likewise, it was observed that the steel fibres addition into the blended concrete mixture (RBC) had decreased the mortar workability, as seen in Fig. (2). This reduction can attribute to that fibres raise the viscosity of concrete by absorbing water from the cement paste [46]. Also, the inclusion of steel fibres into concrete mixes restricts the particle mobility of concrete and then reducing the mortar flow especially with improving the content and the length of steel fibres [47, 48]. Particularly, square steel fibres (CSFs) have resulted in the highest flowability reduction in comparison with other concrete batches produced with SSFs and HEFs under the same lengths and volume fractions (Fig. 2). This can attribute to that square steel fibres have a higher resistance to the concrete movement due to their geometries. Thus, the highest demand for superplasticizer $(\mathrm{SP} \%)$ of 1.6 was obtained from concrete batches manufactured with mix 29. While concrete mixtures involved SSFs showed higher slump values compared to those were produced with CSFs and HEFs under the same fibre content and length. This refers to that SSFs involve less resistance to the green concrete movement, since they do not involve mechanical anchorages. On the other hands, the experimental outcomes indicated that the addition of SF7\% has reduced the air content of the blended concrete (RBC) by $18 \%$ in comparison with that of RPC. While it was indicated that the air content of fibre-reinforced concrete batches has increased with improving steel fibre percentages and lengths (Fig. 3). More specifically, fibres tend to capture more air particles during the blending procedure. Also, the space- filling abilities of applied steel fibres can also contribute to determining the air content of concrete mixtures.

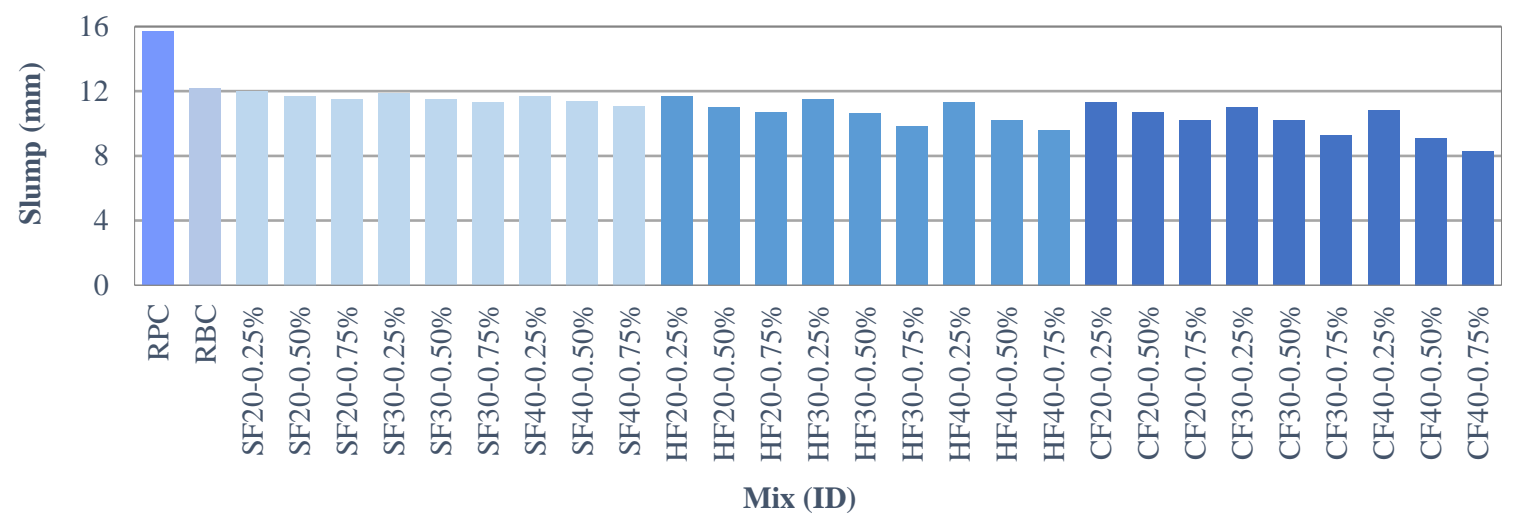

Fig. (2). Slump test results. 


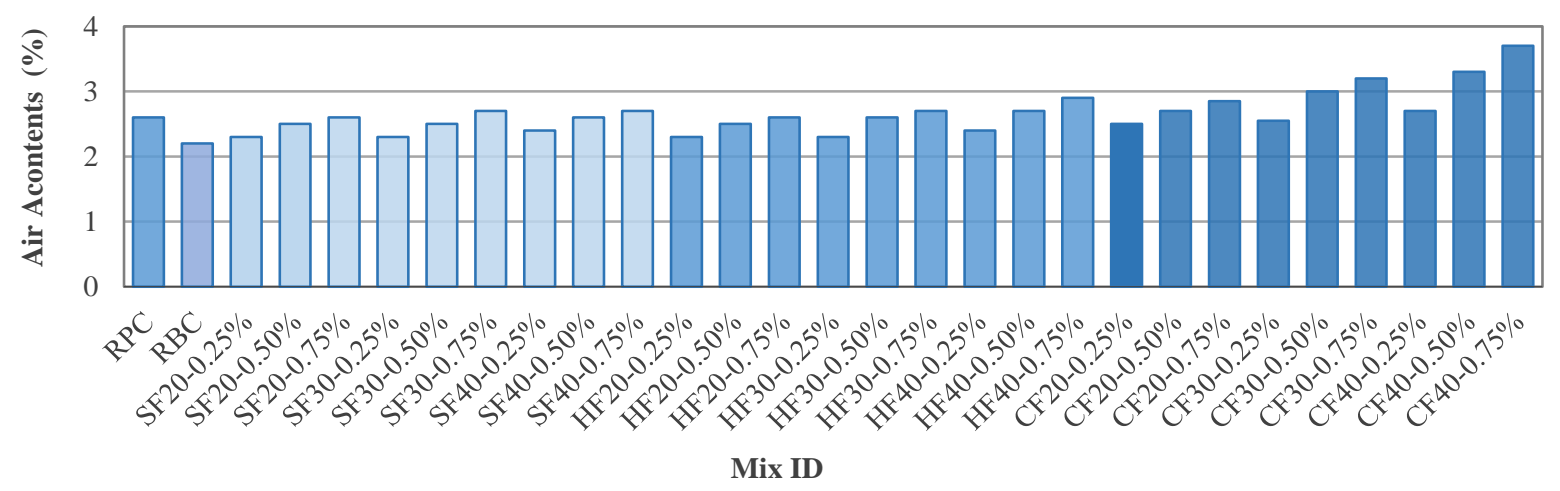

Fig. (3). Air content test results.

\subsection{Hardened Properties}

\subsubsection{Concrete Compressive Strength}

The 28 days compressive strength results of different concrete mixtures are demonstrated in Fig. (4). The paper findings showed a considerable growth of $19 \%$ in the concrete compressive strength with replacing $7 \%$ of OPC by SF. The current paper results emphasize the previous outcomes related to the efficiency of substitution a part of cement with mineral admixtures to produce pozzolanic or blended concrete. The inclusion of supplementary materials i.e. SF, MK, FA, etc. into concrete mixture results in significant reductions in the concrete porosity by improving the bonding strength between concrete components (cement paste and aggregates) [32]. Therefore, the blended concrete tends to be denser, more impermeable, and durable than the normal strength concrete. Consequently, that reflects positively on the compressive strength outcomes $[4,49,50]$. On the other hands, paper results indicated that the inclusion of steel fibres into blended concrete mixtures (RBC) involved different impacts on the concrete compressive strength values, depending on the geometries and volume fractions of applied steel fibres. For instance, concrete specimens produced with SSFs and HEFs have shown higher 28 days compressive strength results up to $5 \%$ (SF40-0.75\%), and $4 \%$ (HF $40-0.50 \%$ ) compared to that of RBC. While, the compressive strength values of concrete samples, manufactured with Closed Steel Fibres (CSFs), have decreased with increasing fibre lengths and volume fraction (Fig. 4). The max compressive strength reduction of $9 \%$ has been obtained from the concrete sample produced with mix 29 (CF40-0.75\%) compared to that of RBC. This strength reduction may attribute to an increase in the CSF percentages may adversely impact the packing density of concrete owing to their poor space-filling abilities. Especially, CSF40 could demonstrate less consistency with other concrete constituents due to their high areas compared to those produced with CSF20. Consequently, that might contribute to increasing the permeability of concrete specimens and then reducing their compressive strength values. Thus, the current paper outcomes are in disagreement with some previous findings that the fibre usage in any form and volume fraction leads to the important compressive strength improvement $[4,32,33]$. While, other works have stated the noteworthy effects of inclusion steel fibres on the concrete compressive strength [35, 36, 51, 52].

\subsubsection{Concrete Splitting Tensile Strength}

The 28 days splitting tensile strength outcomes of different concrete mixtures are summarized in Table $\mathbf{4}$ and shown in Fig.(5). The current paper outcomes indicated that the addition of $\mathrm{SF} 7 \%$ resulted in the higher concrete splitting tensile strength enhancement up to $6 \%$ compared to that of RPC. It is agreed that introducing mineral admixtures (SF, MK, FA, etc.) into concrete mixes can enhance the structure of the concrete matrix by improving the bonding strength between cement paste and unreacted materials (aggregates, fibres, etc.). The bond strength enhancement is a result of the modification of calcium hydroxide (formed on the aggregate particles) into hydrated calcium silicate in the reactive addition $[4,17,32,53$, 54]. As a result, the permeability of the blended concrete reduces and that reflects positively on the concrete performance. Paper results also stated that the inclusion of steel fibres into blended concrete mixtures included significant effects on improving the concrete splitting tensile strength, depending on the geometry and content of used steel fibres. More specifically, hooked end steel fibres (HEF40) exhibited the highest splitting tensile strength enhancement of $20 \%$ (HF40-0.75\%) in comparison with that of RBC. It was also noticed that the splitting tensile strength of concrete samples manufactured with HEFs and SSFs has improved considerably with increasing the fibre volume fraction (Table 4). For instance, the splitting tensile strength improvements resulted by mix 18 (HF40-25\%), mix 19 (HF40-0.50\%), and mix 20 (HF40-0.75\%) were $6 \%, 14 \%$, and $20 \%$, respectively compared to that of the RBC. Specifically, improving steel fibre percentages can considerably enhance the viscosity and yield stress of cementitious based materials owing to the friction growth between steel fibres and their interactions with solid constituents [55]. The experimental results also showed that increase the length of HEFs and SSFs to $40 \mathrm{~mm}$ exhibited higher splitting tensile improvements up to $13 \%$ (HF40-75\%), and $8 \%$ (SF40-75\%) compared to those of mix 14 (HF20-75\%) and mix 5 (SF20-75\%), respectively. 


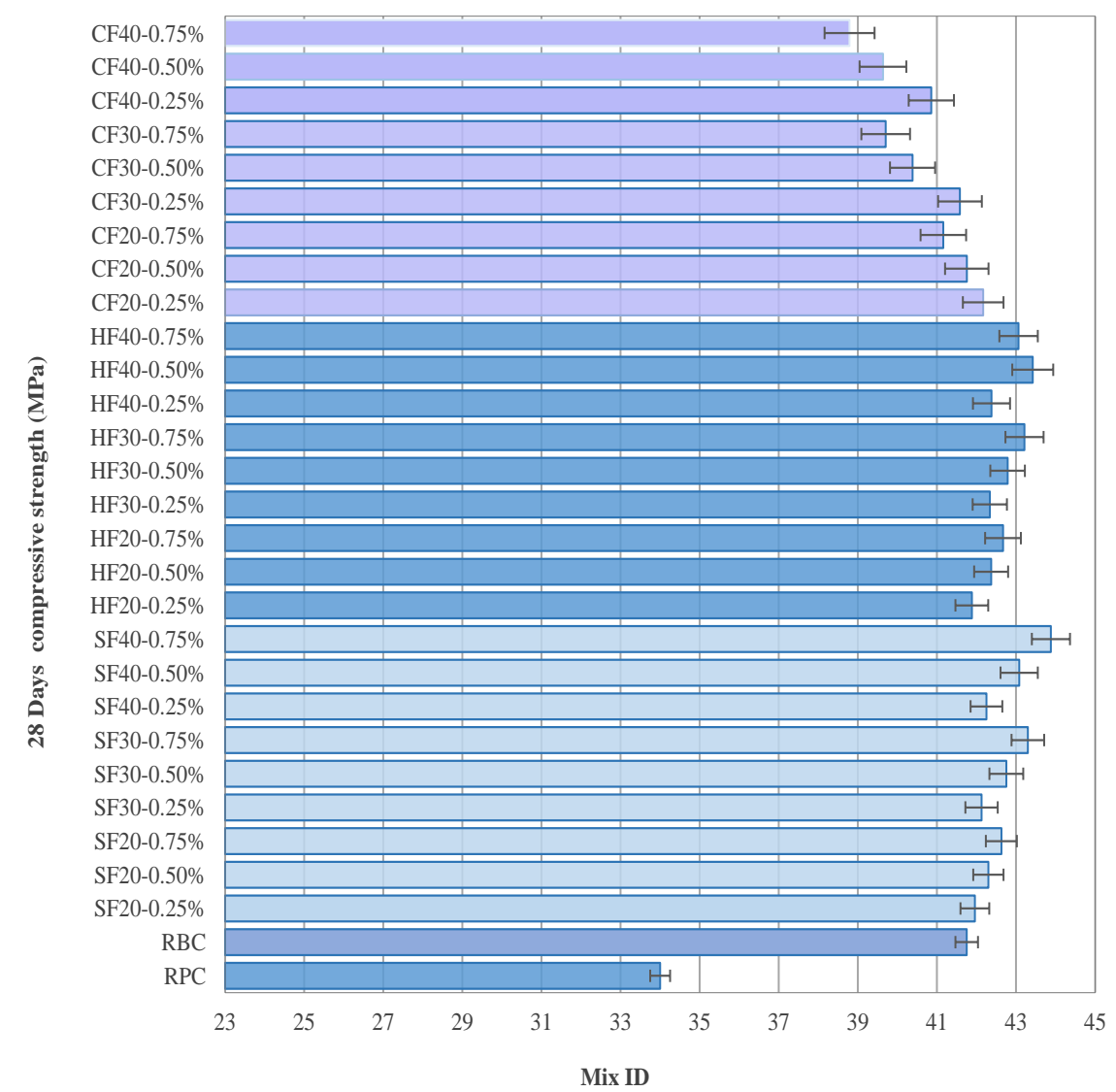

Fig. (4). Concrete compressive strength results.

Table 4. Splitting tensile strength, and flexural strength results.

\begin{tabular}{|c|c|c|c|}
\hline Mix No. & Mixture ID & 28 Days Concrete Splitting Tensile Strength (MPa) & 28 Days Concrete Flexural Strength (MPa) \\
\hline 1 & RPC & 3.12 & 3.37 \\
\hline 2 & RBC & 3.31 & 3.54 \\
\hline 3 & SF20-0.25\% & 3.35 & 3.58 \\
\hline 4 & SF20- $0.50 \%$ & 3.38 & 3.64 \\
\hline 5 & SF20-0.75\% & 3.43 & 3.70 \\
\hline 6 & SF30-0.25\% & 3.39 & 3.63 \\
\hline 7 & SF30-0.50\% & 3.50 & 3.75 \\
\hline 8 & SF30-0.75\% & 3.59 & 3.84 \\
\hline 9 & SF40-0.25\% & 3.42 & 3.65 \\
\hline 10 & SF40-0.50\% & 3.57 & 3.82 \\
\hline 11 & SF40-0.75\% & 3.68 & 3.94 \\
\hline 12 & HF20-0.25\% & 3.38 & 3.63 \\
\hline 13 & HF20-0.50\% & 3.47 & 3.74 \\
\hline 14 & HF20-0.75\% & 3.60 & 3.82 \\
\hline 15 & HF30- $0.25 \%$ & 3.46 & 3.69 \\
\hline 16 & HF30- $0.50 \%$ & 3.62 & 3.89 \\
\hline 17 & HF30- $0.75 \%$ & 3.87 & 4.07 \\
\hline 18 & HF40-0.25\% & 3.53 & 3.72 \\
\hline 19 & HF40-0.50\% & 3.84 & 4.04 \\
\hline 20 & HF40-0.75\% & 4.11 & 3.32 \\
\hline 21 & CF20-0.25\% & 3.38 & 3.68 \\
\hline 22 & CF20-0.50\% & 3.47 & \\
\hline & & & \\
\hline
\end{tabular}


(Table 4) contd.....

\begin{tabular}{|c|c|c|c|}
\hline Mix No. & Mixture ID & 28 Days Concrete Splitting Tensile Strength (MPa) & 28 Days Concrete Flexural Strength (MPa) \\
\hline 23 & CF20-0.75\% & 3.55 & 3.77 \\
\hline 24 & CF30-0.25\% & 3.36 & 3.61 \\
\hline 25 & CF30-0.50\% & 3.43 & 3.70 \\
\hline 26 & CF30-0.75\% & 3.52 & 3.79 \\
\hline 27 & CF40-0.25\% & 3.35 & 3.59 \\
\hline 28 & CF40-0.50\% & 3.39 & 3.64 \\
\hline 29 & CF40-0.75\% & 3.47 & 3.74 \\
\hline
\end{tabular}
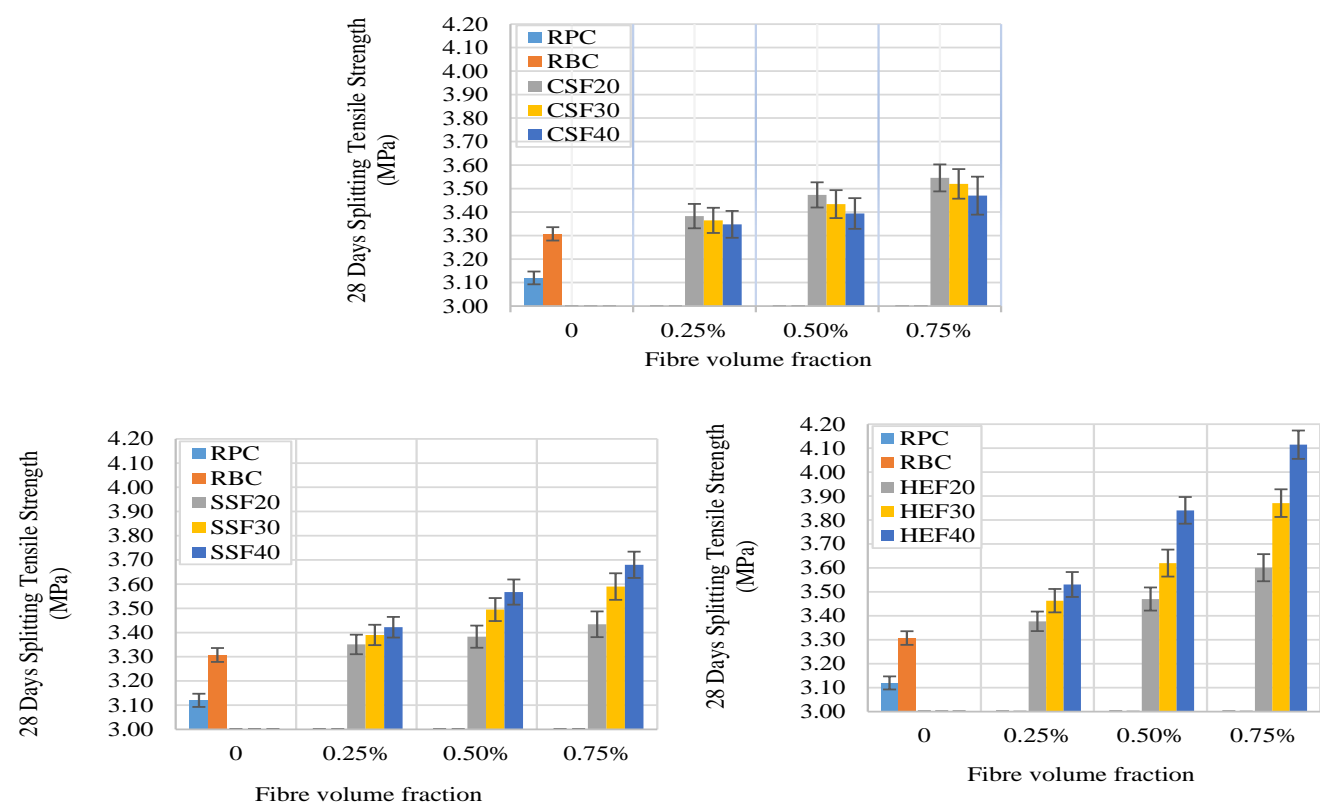

Fig. (5). Splitting tensile strength results.
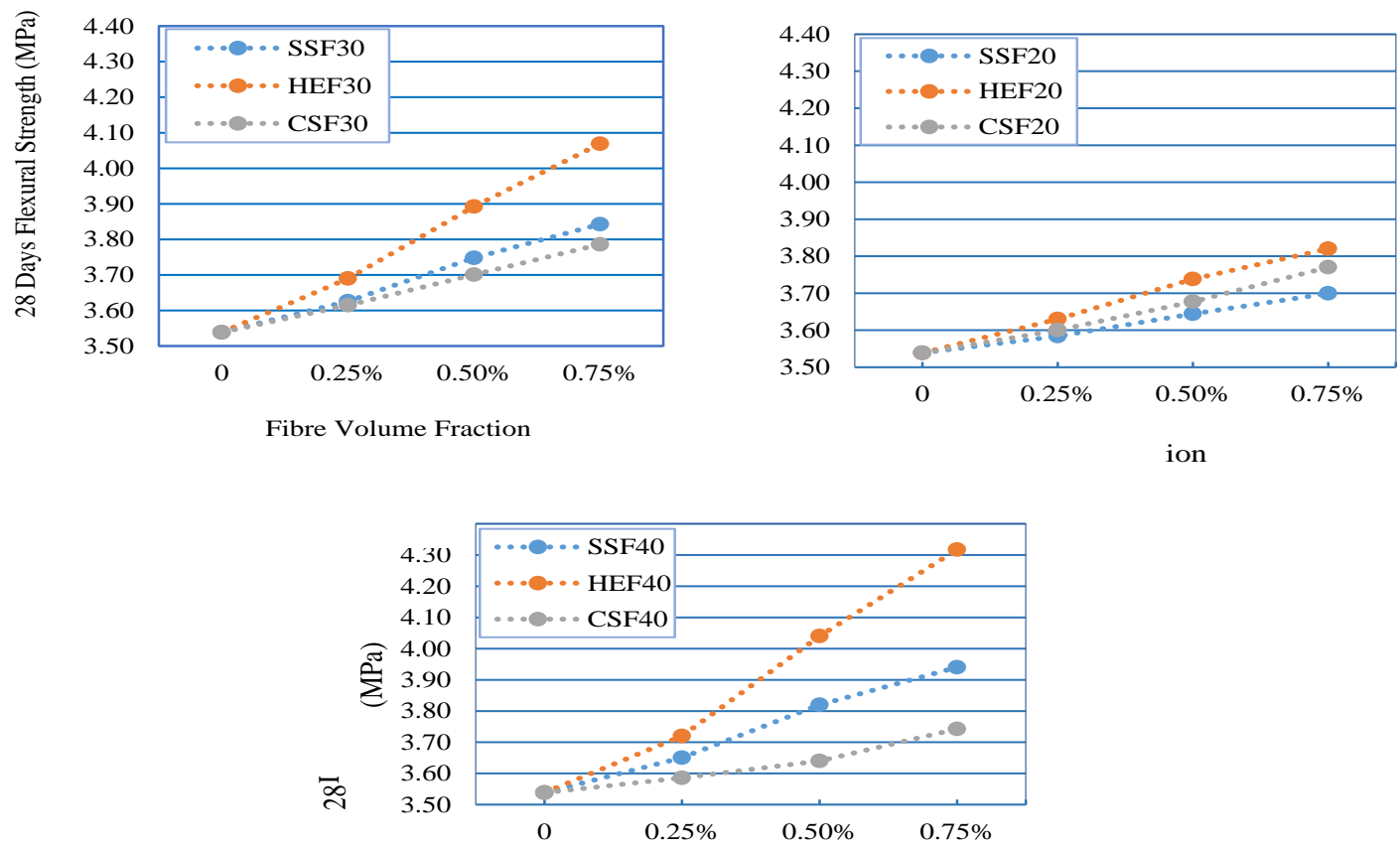

Fig. (6). Flexural strength results. 
On the other hand, CSF20 has resulted in higher splitting tensile strength development of 7\% (CF20-0.75\%) compared to that of RBC. It was also higher by $3 \%$ in comparison with that of mix 5 (SF20-0.75\%), and lower by $2 \%$ than that of mix 14 (HF20-0.75\%). The additional strength enhancement achieved by CSF20 compared to that of SSFs can refer to their high performance against the pulling-out effect from the concrete matrix. Especially, the failure of closed steel fibre specimens wasn't initiated by pulling out of CSFs. However, the splitting tensile strength of most concrete specimens manufactured with CSFs has decreased with increasing fibre lengths under the same volume fraction (Fig. 5). The splitting tensile strength reduction resulted from CSFs could be induced by several causes. More specifically, CSFs were ineffective regarding the filling space ability because of their geometries compared to those of HEFs and SSFs. This was concluded from the air content results of CSF mixtures (Fig. 3). Then, that contributed to increasing the permeability of concrete specimens produced with CSF mixtures. In addition, the dispersion of CSFs into concrete structures was less than those of HEFs, and SSFs for the same volume fraction, because each CSF equals four HEFs or SSFs. Furthermore, an increase in the length of CSFs has reduced their dispersion into the concrete structure and that has reflected adversely on the concrete splitting tensile strength. Therefore, CSF20 showed better dispersion and consistency than those manufactured with higher lengths. Thus, it is recommended to apply steel fibres with appropriate geometries to maintain the concrete mixture homogeneity, especially if the concrete mixture involves high percentages of coarse aggregate and fibres.

\subsubsection{Concrete Flexural Strength}

The flexural strength results of this paper are involved in Table 4 and graphically demonstrated in Fig. (6). The paper findings asserted that the substitution of $7 \%$ OPC with SF resulted in a slight flexural strength improvement up to $5 \%$ compared to that of RPC. This improvement attributes to the pozzolanic properties of SF, which contribute to enhancing the performance of concrete material such as permeability and durability [32, 54]. While it was observed that steel fibre inclusions have led to considerable flexural strength developments, depending on the geometries and percentages of applied steel fibres (Fig. 6). For example, concrete specimens produced with mix 20 (HF40-0.75\%) showed a significant flexural strength enhancement up to $18 \%$ in comparison with that of RBC. This strength growth refers to that Hooked End Steel Fibres (HEFs) involve high performance in restricting the growth of macro concrete cracks due to their effective mechanical anchorages in addition to their high tensile strengths, as well as elastic modulus. While SSFs contributed to the flexural strength enhancement up $10 \%$ (SF40-0.75\%) in comparison to that of RBC. Most previous findings asserted that the pulling out loads of straight steel fibres are highly lower than those of non-straight steel fibres such as cone end, hooked end, crimped, and twisted steel fibres [31, 35, 56]. Paper findings also showed that the bending strength enhancements of HEFs and SSFs have increased with improving fibre volume fraction (Fig. 6). Furthermore, the current paper findings revealed that improving HEFs and SSFs lengths have demonstrated higher flexural strength improvements up to $12 \%$ (HF40-75\%), and 7\% (SF40-75\%) compared to those of mix 14 (HF20-75\%) and mix 5 (SF20-75\%), respectively. Improving the steel fibres aspect ratio (the fibre length (L)/ the fibre diameter (d)) can enhance the fibre mechanical interaction [55, 57]. Also, concrete specimen produced with CSFs exhibited higher flexural strength improvement up to $6 \%$ (CF30-0.75\%) compared to that of RBC. Most flexural strength results of concrete specimens produced with CSFs were less than those manufactured with HEFs and SSFs under the same fibre length and volume fraction (Table 4). Also, improving CSF length to $40 \mathrm{~mm}$ has decreased the 28 days concrete flexural strength compared to that of CSF30 and CSF20, respectively (Table 4). This reduction may refer to that concrete specimen produced with CSF40 showed less fibre dispersion, alignment, and higher percentages of air voids than those produced with CSF30 and CSF20. Although it is significant to develop the geometry of steel fibres against pulling out from surrounding concrete to use their max capacities, it must be considered that this development does not adversely impact the performance of concrete materials. Thus, further research is desired to consider the effect concrete design on the efficiency of closed steel fibres.

\section{CONCLUSION}

Pulling out steel fibers from concrete structures is one of the most common issues encountered in the fiber-reinforced concrete, which impedes using their maximum capacities. Therefore, in this research, the effects of including different lengths and percentages of closed steel fibres on the fresh and hardened concrete characteristics were evaluated. The experimental procedure of this paper included 29 different concrete mixtures, 9 concrete mixtures prepared with each fibre type including straight steel fibres, hooked end steel fibres and closed steel fibre, as well as two reference mixtures (without steel fibres), one produced with plain cement and other with blended silica fume cement. According to the experimental results, the conclusion could be summarized as follows.

- The inclusion of silica fume and steel fibres into concrete mixture decreased the concrete flowability depending on the silica fume content, as well as fibre geometry and percentage. Closed steel fibre concrete demonstrated lower slump values especially with high fibre volume fractions in comparison with those of straight steel fibres and hooked end steel fibres.

- The inclusion of silica fume reduced the air content of concrete due to its pozzolanic effects on improving the performance of the concrete material. While the addition of steel fibres into the concrete samples increased their air contents especially with improving steel fibre lengths and percentages. The concrete samples produced with closed steel fibres exhibit higher air contents than those of straight steel fibres and hooked end steel fibres with the same fibre content, which may attribute to their poor space-filling abilities.

- The addition of $7 \%$ silica fume into concrete mixes contributes to significant enhancement in the 28-day concrete compressive strength. While the inclusions of 
straight steel fibres and hooked end steel fibres into concrete mixes exhibit slight concrete compressive strength improvements in comparison with that of the reference blended concrete. Whereas the incorporation of closed steel fibres into concrete mixes declines the concrete compressive strength, especially at a high fibre volume fraction of $50 \%$ and $75 \%$.

- The incorporation of $7 \%$ silica fume into concrete mixes involves a slight effect on enhancing the 28-day concrete flexural strength and splitting tensile strength compared to those of fibre-reinforced concrete specimens. closed steel fibres demonstrate better behaviour against the effect of pulling out from the surrounding concrete than those of straight steel fibres and hooked end steel fibres. However, the addition of closed steel fibres increased the permeability of concrete specimens due to their poor space-filling abilities.

- Increasing the length of straight steel fibres and hooked end steel fibres from $20 \mathrm{~mm}$ to $40 \mathrm{~mm}$ improved the concrete flexural and splitting tensile strength depending on the applied fibre volume fraction. While improving the length of closed steel fibres from $20 \mathrm{~mm}$ to $40 \mathrm{~mm}$ declined the concrete bending and splitting tensile strengths.

\section{CONSENT FOR PUBLICATION}

Not applicable

\section{AVAILABILITY OF DATA AND MATERIALS}

The data supporting the findings of the article are available within the paper.

\section{FUNDING}

None.

\section{CONFLICT OF INTEREST}

The author declares no conflict of interest, financial or otherwise. Dr. Ali Bagheri is the Editorial Board Member of the TOCIEJ.

\section{ACKNOWLEDGEMENTS}

Declared none.

\section{REFERENCES}

[1] E. Aprianti, "A huge number of artificial waste material can be supplementary cementitious material (SCM) for concrete production-A review part II", J. Clean. Prod., vol. 142, pp. 4178-4194, 2017. [http://dx.doi.org/10.1016/j.jclepro.2015.12.115]

[2] Q-f. Liu, "Ionic transport features in concrete composites containing various shaped aggregates: A numerical study", Compos. Struct., vol. 183, pp. 371-380, 2018.

[http://dx.doi.org/10.1016/j.compstruct.2017.03.088]

[3] S. Al-Qutaifi, A. Nazari, and A. Bagheri, "Mechanical properties of layered geopolymer structures applicable in concrete 3D-printing", Constr. Build. Mater., vol. 176, pp. 690-699, 2018. [http://dx.doi.org/10.1016/j.conbuildmat.2018.04.195]

[4] V. Afroughsabet, and T. Ozbakkaloglu, "Mechanical and durability properties of high-strength concrete containing steel and polypropylene fibres", Constr. Build. Mater., vol. 94, pp. 73-82, 2015. [http://dx.doi.org/10.1016/j.conbuildmat.2015.06.051]

[5] J.C. Lim, and T. Ozbakkaloglu, "Influence of silica fume on stress-strain behavior of FRP-confined HSC", Constr. Build. Mater., vol. 63, pp. 11-24, 2014.

[http://dx.doi.org/10.1016/j.conbuildmat.2014.03.044]

[6] G. Karthikeyan, High-Performance Concrete (HPC)—An Innovative Cement Concrete Mix Design to Increase the Life Span of Structures, in Sustainable Construction and Building Materials., Springer., 2019, pp. 2083-2089.

[7] H. Yazic1, "The effect of curing conditions on compressive strength of ultra high strength concrete with high volume mineral admixtures", Build. Environ., vol. 42, no. 5, pp. 2083-2089, 2007.

[http://dx.doi.org/10.1016/j.buildenv.2006.03.013]

[8] N. Zod, and A.M. Soliman, Grout fot two-stage alkali activated concrete., 2019.

[9] J. Xie, "Effects of combined usage of GGBS and fly ash on workability and mechanical properties of alkali activated geopolymer concrete with recycled aggregate", Compos., Part B Eng., vol. 164, pp. 179-190, 2019.

[http://dx.doi.org/10.1016/j.compositesb.2018.11.067]

[10] D. Shen, "Early-age behavior and cracking resistance of high-strength concrete reinforced with Dramix 3D steel fibre", Constr. Build. Mater., vol. 196, pp. 307-316, 2019.

[http://dx.doi.org/10.1016/j.conbuildmat.2018.10.125]

[11] P. Rattanachu, W. Tangchirapat, and C. Jaturapitakkul, "Water permeability and sulfate resistance of eco-friendly high-strength concrete composed of ground bagasse ash and recycled concrete aggregate", J. Mater. Civ. Eng., vol. 31, no. 6, 2019.04019093 [http://dx.doi.org/10.1061/(ASCE)MT.1943-5533.0002740]

[12] S.K. Das, Effect of rice husk ash and silica fume as strength-enhancing materials on properties of modern concrete-A comprehensive review. Emerg. Trends. Civi. Engineer., Springer, 2020, pp. 253-266. [http://dx.doi.org/10.1007/978-981-15-1404-3_21]

[13] A.M. Ahmed, "Physical properties of geopolymer concrete incorporating silica fume and ground granulated blast-furnace slag", Int. J. Sci. Res. (Ahmedabad), vol. 4, pp. 2415-2419, 2015.

[14] S. Dadsetan, and J. Bai, "Mechanical and microstructural properties of self-compacting concrete blended with metakaolin, ground granulated blast-furnace slag and fly ash", Constr. Build. Mater., vol. 146, pp. 658-667, 2017.

[http://dx.doi.org/10.1016/j.conbuildmat.2017.04.158]

[15] J. Khatib, and S. Wild, "Pore size distribution of metakaolin paste", Cement Concr. Res., vol. 26, no. 10, pp. 1545-1553, 1996. [http://dx.doi.org/10.1016/0008-8846(96)00147-0]

[16] P. Song, and S. Hwang, "Mechanical properties of high-strength steel fibre-reinforced concrete", Constr. Build. Mater., vol. 18, no. 9, pp. 669-673, 2004.

[http://dx.doi.org/10.1016/j.conbuildmat.2004.04.027]

[17] M. Nili, and V. Afroughsabet, "The effects of silica fume and polypropylene fibres on the impact resistance and mechanical properties of concrete", Constr. Build. Mater., vol. 24, no. 6, pp. 927-933, 2010.

[http://dx.doi.org/10.1016/j.conbuildmat.2009.11.025]

[18] P. Rashiddadash, A.A. Ramezanianpour, and M. Mahdikhani, "Experimental investigation on flexural toughness of hybrid fibre reinforced concrete (HFRC) containing metakaolin and pumice", Constr. Build. Mater., vol. 51, pp. 313-320, 2014.

[http://dx.doi.org/10.1016/j.conbuildmat.2013.10.087]

[19] O. Kayali, M. Haque, and B. Zhu, "Some characteristics of high strength fibre reinforced lightweight aggregate concrete", Cement Concr. Compos., vol. 25, no. 2, pp. 207-213, 2003. [http://dx.doi.org/10.1016/S0958-9465(02)00016-1]

[20] A. Sharma, "Experimental investigations on mechanical and radiation shielding properties of hybrid lead-steel fibre reinforced concrete", Nucl. Eng. Des., vol. 239, no. 7, pp. 1180-1185, 2009.

[http://dx.doi.org/10.1016/j.nucengdes.2009.02.017]

[21] F. Köksal, "Combined effect of silica fume and steel fibre on the mechanical properties of high strength concretes", Constr. Build. Mater., vol. 22, no. 8, pp. 1874-1880, 2008.

[http://dx.doi.org/10.1016/j.conbuildmat.2007.04.017]

[22] A.E. Naaman, High performance fibre reinforced cement composites: classification and applications.CBM-CI international workshop, Karachi, Pakistan., Citeseer., 2007.

[23] X. Hou, "Effect of fire insulation on fire resistance of hybrid-fibre reinforced reactive powder concrete beams", Compos. Struct., vol. 209, pp. 219-232, 2019.

[http://dx.doi.org/10.1016/j.compstruct.2018.10.073]

[24] A.E. Naaman, and H.W. Reinhardt, High performance fibre reinforced cement composites 2 (HPFRCC2)., 1996. 
[25] G.J. Parra-Montesinos, "High-performance fibre-reinforced cement composites: An alternative for seismic design of structures", $A C I$ Struct. J., vol. 102, no. 5, p. 668, 2005.

[26] M. Nataraja, T. Nagaraj, and S. Basavaraja, "Reproportioning of steel fibre reinforced concrete mixes and their impact resistance", Cement Concr. Res., vol. 35, no. 12, pp. 2350-2359, 2005. [http://dx.doi.org/10.1016/j.cemconres.2005.06.011]

[27] V. Mechtcherine, "Mineral-impregnated carbon fibre composites as novel reinforcement for concrete construction: Material and automation perspectives", Autom. Construct., vol. 110, 2020.103002 [http://dx.doi.org/10.1016/j.autcon.2019.103002]

[28] A.M. Brandt, "Fibre reinforced cement-based (FRC) composites after over 40 years of development in building and civil engineering", Compos. Struct., vol. 86, no. 1-3, pp. 3-9, 2008.

[http://dx.doi.org/10.1016/j.compstruct.2008.03.006]

[29] M. Hassanpour, P. Shafigh, and H.B. Mahmud, "Lightweight aggregate concrete fibre reinforcement-A review", Constr. Build. Mater., vol. 37, pp. 452-461, 2012.

[http://dx.doi.org/10.1016/j.conbuildmat.2012.07.071]

[30] S. Iqbal, "Mechanical properties of steel fibre reinforced high strength lightweight self-compacting concrete (SHLSCC)", Constr. Build. Mater., vol. 98, pp. 325-333, 2015.

[http://dx.doi.org/10.1016/j.conbuildmat.2015.08.112]

[31] A. Islam, "Influence of steel fibres on the mechanical properties and impact resistance of lightweight geopolymer concrete", Constr. Build. Mater., vol. 152, pp. 964-977, 2017.

[http://dx.doi.org/10.1016/j.conbuildmat.2017.06.092]

[32] M. Nili, and V. Afroughsabet, "Combined effect of silica fume and steel fibres on the impact resistance and mechanical properties of concrete", Int. J. Impact Eng., vol. 37, no. 8, pp. 879-886, 2010 [http://dx.doi.org/10.1016/j.ijimpeng.2010.03.004]

[33] E. Badogiannis, K. Christidis, and G. Tzanetatos, "Evaluation of the mechanical behavior of pumice lightweight concrete reinforced with steel and polypropylene fibres", Constr. Build. Mater., vol. 196, pp. 443-456, 2019.

[http://dx.doi.org/10.1016/j.conbuildmat.2018.11.109]

[34] K.H. Mo, "Mechanical, toughness, bond and durability-related properties of lightweight concrete reinforced with steel fibres", Mater. Struct., vol. 50, no. 1, p. 46, 2017.

[http://dx.doi.org/10.1617/s11527-016-0934-1]

[35] S. Iqbal, "Enhanced mechanical properties of fibre reinforced concrete using closed steel fibres", Mater. Struct., vol. 52, no. 3, p. 56, 2019. [http://dx.doi.org/10.1617/s11527-019-1357-6]

[36] V. Afroughsabet, L. Biolzi, and T. Ozbakkaloglu, "Influence of double hooked-end steel fibres and slag on mechanical and durability properties of high performance recycled aggregate concrete", Compos. Struct., vol. 181, pp. 273-284, 2017.

[http://dx.doi.org/10.1016/j.compstruct.2017.08.086]

[37] M. Leone, "Fibre-reinforced concrete with low content of recycled steel fibre: Shear behaviour", Constr. Build. Mater., vol. 161, pp. 141-155, 2018.

[http://dx.doi.org/10.1016/j.conbuildmat.2017.11.101]

[38] L. Jin, "Experimental investigation on static and dynamic mechanical properties of steel fibre reinforced ultra-high-strength concretes", Constr. Build. Mater., vol. 178, pp. 102-111, 2018.

[http://dx.doi.org/10.1016/j.conbuildmat.2018.05.152]

[39] D. Soulioti, "Effects of fibre geometry and volume fraction on the flexural behaviour of steel-fibre reinforced concrete", Strain, vol. 47, pp. e535-e541, 2011.

[http://dx.doi.org/10.1111/j.1475-1305.2009.00652.x]

[40] A. Standard, Standard test method for slump of hydraulic-cement concrete., ASTM Annual Book of ASTM Standards, 2015.
[41] A. C138/C138M-16a, Standard test method for density (unit weight), yield, and air content (gravimetric) of concrete., ASTM International West Conshohocken, PA., 2016.

[42] A.I.C.C.o. Concrete, and C. Aggregates, Standard test method for compressive strength of cylindrical concrete specimens., ASTM International, 2014

[43] C. ASTM, Standard test method for splitting tensile strength of cylindrical concrete specimens., 2011.

[44] ASTM, Standard test method for flexural performance of fibrereinforced concrete (using beam with third-point loading)., United States, 2010.

[45] J. Punkki, J. Golaszewski, and O.E. Gjørv, "Workability loss of highstrength concrete", ACI Mater. J., vol. 93, pp. 427-431, 1996.

[46] F. Hasan-Nattaj, and M. Nematzadeh, "The effect of forta-ferro and steel fibres on mechanical properties of high-strength concrete with and without silica fume and nano-silica", Constr. Build. Mater., vol. 137, pp. 557-572, 2017.

[http://dx.doi.org/10.1016/j.conbuildmat.2017.01.078]

[47] M. Hsie, C. Tu, and P. Song, "Mechanical properties of polypropylene hybrid fibre-reinforced concrete", Mater. Sci. Eng. A, vol. 494, no. 1-2, pp. 153-157, 2008.

[http://dx.doi.org/10.1016/j.msea.2008.05.037]

[48] N.A. Libre, "Mechanical properties of hybrid fibre reinforced lightweight aggregate concrete made with natural pumice", Constr. Build. Mater., vol. 25, no. 5, pp. 2458-2464, 2011.

[http://dx.doi.org/10.1016/j.conbuildmat.2010.11.058]

[49] M.M. Johari, "Influence of supplementary cementitious materials on engineering properties of high strength concrete", Constr. Build. Mater., vol. 25, no. 5, pp. 2639-2648, 2011.

[http://dx.doi.org/10.1016/j.conbuildmat.2010.12.013]

[50] E. Güneyisi, M. Gesoğlu, and K. Mermerdaş, "Improving strength, drying shrinkage, and pore structure of concrete using metakaolin", Mater. Struct., vol. 41, no. 5, pp. 937-949, 2008. [http://dx.doi.org/10.1617/s11527-007-9296-z]

[51] J. Gao, W. Sun, and K. Morino, "Mechanical properties of steel fibrereinforced, high-strength, lightweight concrete", Cement Concr. Compos., vol. 19, no. 4, pp. 307-313, 1997.

[http://dx.doi.org/10.1016/S0958-9465(97)00023-1]

[52] A. Hassan, S. Jones, and G. Mahmud, "Experimental test methods to determine the uniaxial tensile and compressive behaviour of ultra high performance fibre reinforced concrete (UHPFRC)", Constr. Build. Mater., vol. 37, pp. 874-882, 2012.

[http://dx.doi.org/10.1016/j.conbuildmat.2012.04.030]

[53] N. Kaid, "Durability of concrete containing a natural pozzolan as defined by a performance-based approach", Constr. Build. Mater., vol. 23, no. 12, pp. 3457-3467, 2009.

[http://dx.doi.org/10.1016/j.conbuildmat.2009.08.002]

[54] M.J. Shannag, and A. Yeginobali, "Properties of pastes, mortars and concretes containing natural pozzolan", Cement Concr. Res., vol. 25, no. 3, pp. 647-657, 1995.

[http://dx.doi.org/10.1016/0008-8846(95)00053-F]

[55] K.H. Khayat, "Rheological properties of ultra-high-performance concrete-An overview", Cement Concr. Res., vol. 124, 2019.105828 [http://dx.doi.org/10.1016/j.cemconres.2019.105828]

[56] R. Breitenbücher, "Experimental, analytical and numerical analysis of the pullout behaviour of steel fibres considering different fibre types, inclinations and concrete strengths", Struct. Concr., vol. 15, no. 2, pp. 126-135, 2014.

[http://dx.doi.org/10.1002/suco.201300058]

[57] B. Hughes, and N. Fattuhi, "The workability of steel-fibre-reinforced concrete", Mag. Concr. Res., vol. 28, no. 96, pp. 157-161, 1976. [http://dx.doi.org/10.1680/macr.1976.28.96.157]

\section{C) 2021 Al-Qutaifi \& Bagheri.}

This is an open access article distributed under the terms of the Creative Commons Attribution 4.0 International Public License (CC-BY 4.0), a copy of which is available at: https://creativecommons.org/licenses/by/4.0/legalcode. This license permits unrestricted use, distribution, and reproduction in any medium, provided the original author and source are credited. 